\title{
Public Health Impact and Cost-Effectiveness of Non-live Adjuvanted Recombinant Zoster Vaccine in Canadian Adults
}

\author{
Ashleigh McGirr ${ }^{1}\left[\right.$ Desiree Van Oorschot ${ }^{2} \cdot$ Robyn Widenmaier $^{1} \cdot$ Michael Stokes $^{3} \cdot$ Michael L. Ganz $^{4}$. \\ Hyosung Jung ${ }^{4} \cdot$ Lijoy Varghese $^{5} \cdot$ Desmond Curran $^{2}$
}

Published online: 28 June 2019

(c) The Author(s) 2019

\begin{abstract}
Objectives In Canada, incidences of herpes zoster (HZ) and postherpetic neuralgia (PHN) are increasing, posing a significant burden on the healthcare system. This study aimed to determine the public health impact and cost effectiveness of an adjuvanted recombinant zoster vaccine (RZV) compared to no vaccination and to the live attenuated vaccine (ZVL) in Canadians aged 60 years and older.

Methods A multi-cohort Markov model has been adapted to the Canadian context using recent demographic and epidemiologic data. Simulations consisted of age-cohorts annually transitioning between health states. Health outcomes and costs were discounted at $1.5 \%$ per year. The perspective of the Canadian healthcare payer was adopted. A coverage of $80 \%$ for the first RZV and ZVL dose and a compliance of $75 \%$ for the second RZV dose were assumed.

Results RZV was estimated to be cost effective compared with no vaccination with an incremental cost-effectiveness ratio (ICER) of $\$ 28,360$ (Canadian dollars) per quality-adjusted life-year (QALY) in persons aged $\geq 60$ years, avoiding 554,504 HZ and 166,196 PHN cases. Compared with ZVL, RZV accrued more QALYs through the remaining lifetime and an increase in costs of approximately $\$ 50$ million resulting in an average ICER of $\$ 2396$. Results were robust under deterministic and probabilistic sensitivity analyses. HZ incidence rate and persistence of vaccine efficacy had the largest impact on cost effectiveness. Conclusions The cost-utility analysis suggested that RZV would be cost effective in the Canadian population compared with no vaccination and vaccination with ZVL at a willingness-to-pay threshold of $\$ 50,000$.
\end{abstract}

\section{Plain Language Summary}

More than $95 \%$ of adults aged 50 are infected with varicella-zoster virus and are at risk of developing herpes zoster, also known as shingles. This risk is higher in older people and in people with a reduced immune system. Shingles causes a painful rash and may trigger persistent pain and other complications that greatly reduce quality of life. In Canada, Zostavax is the only existing approved vaccine against shingles. It has been offered in a publicly funded program in Ontario to those aged 65-70 years since September 2016. Shingrix, is a new shingles vaccine that has recently been approved by Health Canada for adults aged $\geq 50$ years. The present model suggests that Shingrix confers higher protection against shingles compared to Zostavax, with a greater reduction in shingles episodes. The increase in vaccination costs would be partially offset by reduced healthcare visit and medication expenses. For these reasons, provincial health plans may consider offering Shingrix to people aged $\geq 50$ years.

Electronic supplementary material The online version of this article (https://doi.org/10.1007/s40258-019-00491-6) contains supplementary material, which is available to authorized users.

Ashleigh McGirr

ashleigh.a.mcgirr@gsk.com

GSK, Mississauga, Canada

2 GSK, Wavre, Belgium
3 Evidera, Saint-Laurent, Canada

4 Evidera, Waltham, MA, USA

5 GSK, Singapore, Singapore 


\section{Introduction}

Herpes zoster (HZ) arises in older individuals due to the reactivation of latent varicella zoster virus. Approximately $95 \%$ of all adults aged $\geq 50$ years are infected with varicella zoster virus in their youth and thus at risk of developing $\mathrm{HZ}$ [1]. The life-time risk of developing $\mathrm{HZ}$ for subjects with prior varicella ranges between 15 and $30 \%$ with a sharp increase in $\mathrm{HZ}$ incidence after the age of 50 [2-4]. HZ starts usually with prodromal pain, followed by a painful unilateral rash which lasts approximately 1 month $[5,6]$. In 8-33\% of individuals with herpes zoster, pain persists after the acute phase and develops into postherpetic neuralgia (PHN) [6, 7]. Other complications, including disseminated zoster and neurological complications, may occur and are more frequent and severe in older or immunodeficient individuals [8]. $\mathrm{HZ}$ and its complications severely impact the quality of life of patients by interfering with sleep and activities of daily living due to pain [9]. Direct medical costs due to HZ-, PHN- and HZ-related complications impose a substantial burden to the healthcare system, annually estimated at 68 million Canadian Dollars (referred to as $\$$ hereafter) in Canada [10]. Recent studies have found a steadily increasing trend in the incidence of $\mathrm{HZ}$ over time, beyond that expected by demographic shifts alone $[4,11,12]$. Furthermore, current treatment options, based on antivirals, analgesics, opioids, and tricyclic antidepressants, fail to achieve complete symptom relief leading to low patient satisfaction regarding treatment efficacy $[13,14]$. The burden of HZ on the Canadian healthcare system and patients is expected to increase in the future $[8,15]$.

Zoster Vaccine Live (ZVL, Zostavax), a live attenuated virus vaccine indicated for prevention of $\mathrm{HZ}$, was the only approved vaccine for $\mathrm{HZ}$ in Canada until recently. At the time of analysis, ZVL was offered under a universal vaccination program in Ontario and restricted to people aged 65-70 years [16]. There are several limitations associated with ZVL: (i) vaccine efficacy (VE) against $\mathrm{HZ}$ is lower in older individuals who are at higher risk of developing HZ [12, 17], (ii) VE decreases over time with long-term follow-up data suggesting no remaining protection 8 years after vaccination [18], (iii) ZVL is contraindicated in some patients with primary and acquired immunodeficiency [17].

A non-live adjuvanted recombinant zoster vaccine (RZV, Shingrix) has recently been approved in Canada as a twodose vaccine in persons aged $\geq 50$ years [19]. RZV combines glycoprotein $\mathrm{E}$ with an adjuvant system, $\mathrm{AS} 01_{\mathrm{B}}$, intended to enhance the immunological response to the antigen [20]. The clinical profile of RZV is different from ZVL, with placebo-controlled clinical trials suggesting higher initial VE against $\mathrm{HZ}$ and $\mathrm{PHN}$ and modest waning during the initial 4-year period, although longer follow-up studies are ongoing $[21,22]$.

In June 2018, the National Advisory Committee on Immunization recommended that RZV should be offered to populations aged $\geq 50$ years without contraindications [23]. The Comité sur l'immunisation du Québec has recommended the preferential use of RZV over ZVL [24].

The goal of this study was to evaluate the public health impact and cost effectiveness of RZV compared to (i) no vaccination and (ii) $Z V L$ vaccination in Canadian adults aged $\geq 60$ years from the perspective of the healthcare payer. Secondary analyses were conducted in persons aged $\geq 50$ years.

\section{Methods}

\subsection{Model Overview}

The ZOster ecoNomic Analysis model (Fig. 1) is a static multi-cohort state-transition model that has previously been described in detail $[22,25]$. The model was developed in Microsoft Excel and considers up to five age cohorts [50-59 years $(4,999,600$ individuals), 60-64 years (2,052,670 individuals), $65-69$ years $(1,521,715$ individuals), $70-79$ years (2,075,765 individuals), $\geq 80$ years $(1,347,585$ individuals)] and three vaccination strategies (no vaccination, vaccination with $Z \mathrm{VL}$, or vaccination with RZV, each given once in the lifetime). Multiple age cohorts were modeled to capture age-dependent population heterogeneity including disease incidence, complications, VE, and waning VE (Table 1 and Supplementary Information) [26]. The multi-cohort model simulated the impact of $\mathrm{HZ}$ disease over the remaining lifetime from the year of vaccination, with a cycle length of 1 year. The 1 -year cycle length was chosen as many of the input variables (e.g. HZ incidence) are presented on a per annum basis in the literature. During each annual cycle, cohorts could transition between health states of "No HZ", "HZ", "HZ with PHN", "recovery", "recurrent HZ", and "death" (Fig. 1). Complications of HZ and PHN could occur during the same cycle as episodes of $\mathrm{HZ}$ and PHN. An external, technical validation of the ZONA model was performed in January 2017 by "CHESS in Health" and comprised both a technical validation as well as a scenario analysis.

As Canadian real-world data were unavailable, Canadian $\mathrm{HZ}$ vaccination coverage and compliance were estimated from similar data. Coverage with ZVL and first dose RZV was set to $80 \%$ and varied between 60 and $90 \%$ in sensitivity analyses. Compliance with second dose of RZV was set to $75 \%$ and varied between 45 and $89 \%$ in 
Fig. 1 Schematic overview of cohort Markov model, the ZOster ecoNomic Analysis model (ZONA). $H Z$ herpes zoster, $P H N$ postherpetic neuralgia. Note: the dashed lines indicate death from natural causes or death from HZ, upon which patients will exit the model. The health states shaded in gray-'No HZ' and 'Recover', represent states in which the patient has yet to develop $\mathrm{HZ}$ or has recovered from a previous HZ/PHN episode, respectively, and is currently free of HZ/PHN symptoms. Non-PHN complications include neurological, ocular, cutaneous, and non-pain complications. This figure was first published in Curran [22] and has been reproduced with permission from Human Vaccines and Immunotherapeutics

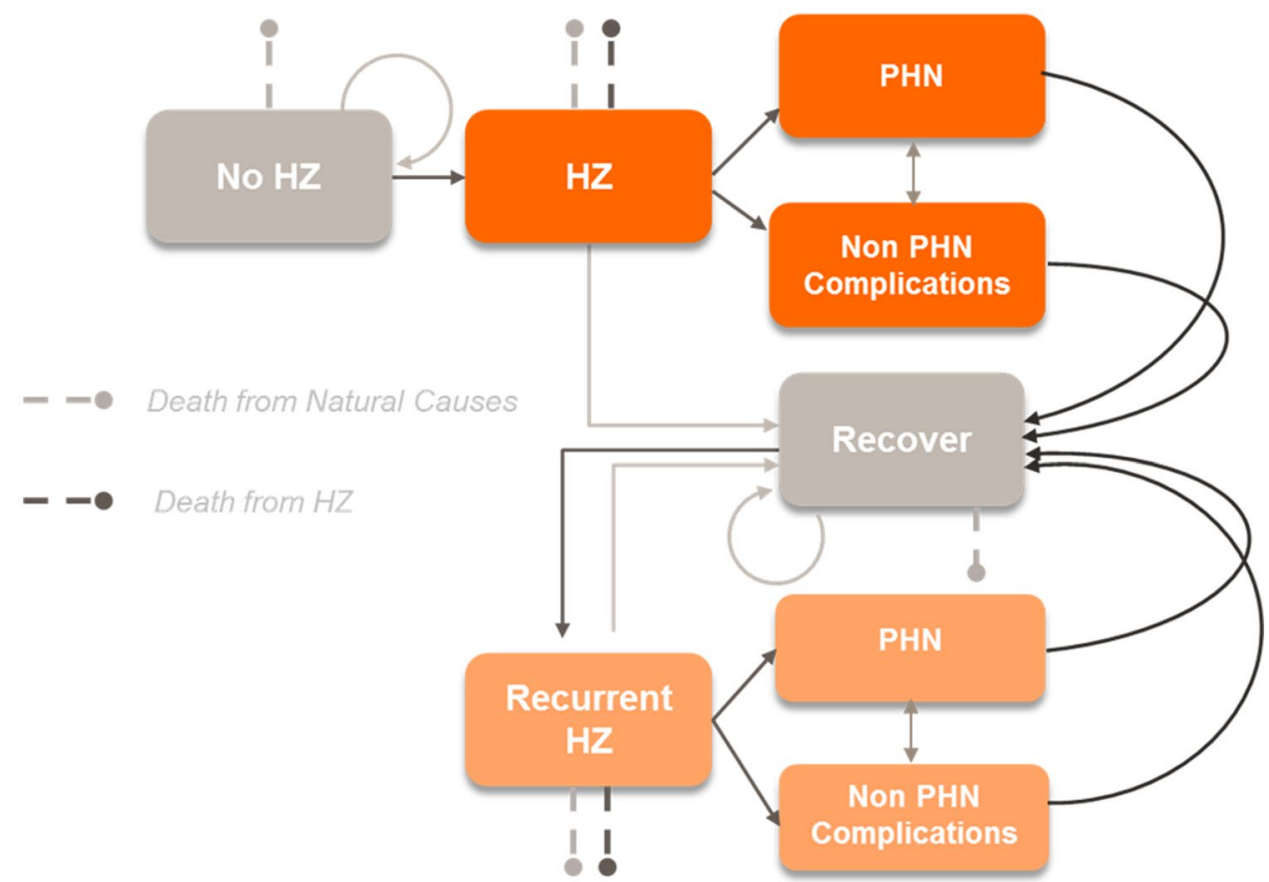

Table 1 Vaccine efficacy base input values and ranges used for sensitivity analyses

\begin{tabular}{|c|c|c|c|c|c|}
\hline Age group (years) & $50-59$ & $60-64$ & $65-69$ & $70-79$ & $\geq 80$ \\
\hline & \multicolumn{5}{|c|}{ RZV vaccine efficacy 2 doses $[21,30]$} \\
\hline $\mathrm{HZ}(\%)$ (range) & $98.4(95.0,100)$ & $98.4(95.0,100)$ & $98.4(95.0,100)$ & $97.84(94.1,100)$ & $97.84(94.1,100)$ \\
\hline \multirow[t]{2}{*}{ PHN (\%) (range) } & $98.4(95.0,100)$ & $98.4(95.0,100)$ & $98.4(95.0,100)$ & $97.84(94.1,100)$ & $97.84(94.1,100)$ \\
\hline & \multicolumn{5}{|c|}{ RZV vaccine efficacy 1 dose [22] } \\
\hline $\mathrm{HZ}(\%)$ (range) & $90.0(58.9,98.9)$ & $90.0(58.9,98.9)$ & $90.0(58.9,98.9)$ & $69.5(24.9,89.1)$ & $69.5(24.9,89.1)$ \\
\hline \multirow[t]{2}{*}{ PHN (\%) (range) } & $90.0(58.9,98.9)$ & $90.0(58.9,98.9)$ & $90.0(58.9,98.9)$ & $69.5(24.9,89.1)$ & $69.5(24.9,89.1)$ \\
\hline & \multicolumn{5}{|c|}{ ZVL vaccine efficacy $[31,32]$} \\
\hline $\mathrm{HZ}(\%)$ (range) & $69.8(54.1,80.6)$ & $63.89(56.0,71.0)$ & $63.89(56.0,71.0)$ & $40.85(28.0,52.0)$ & $18.25(0,48.0)$ \\
\hline PHN (\%) (range) & $69.8(30.8,89.6)$ & $65.69(25.4,84.2)$ & $65.69(25.4,84.2)$ & $73.38(51.6,85.8)$ & $39.51(0,73.8)$ \\
\hline
\end{tabular}

Further definitions and calculations can be found in $\mathrm{SI}$. $\mathrm{VE}_{\mathrm{HZ}}$ and $\mathrm{VE}_{\mathrm{PHN}}$ are vaccine efficacy estimates against herpes zoster and postherpetic neuralgia at year 0 , i.e. immediately after vaccination. These values are not fully aligned with clinical trial data reported in corresponding publications, where $\mathrm{VE}_{\mathrm{HZ}}$ and $\mathrm{VE}_{\mathrm{PHN}}$ are averaged over 3 years

$H Z$ herpes zoster, $P H N$ postherpetic neuralgia, $R Z V$ adjuvanted recombinant zoster vaccine, $V E$ vaccine efficacy, $Z V L$ zoster vaccine live

sensitivity analyses. Base-case and lower-range values were taken from Canadian-specific data on influenza vaccine coverage, assuming higher coverage for the zoster vaccines as they are given once in a life-time compared with annual administration in case of influenza vaccination [27]. Compliance with second dose of RZV was based on a range of plausible values derived from data with multipledose schedules for hepatitis A and varicella and clinical trial data with RZV [22, 28].

Annual discount rates of $1.5 \%$ for costs and qualityadjusted life-years (QALYs) were used in line with recent Canadian Agency for Drugs and Technologies in Health guidelines [29]. Other discount rates $(0 \%, 3 \%$ and $5 \%)$ were used in sensitivity analyses. In accordance with the National Advisory Committee on Immunization recommendation published at the time of analysis, the base-case analysis included adults aged $\geq 60$ years, while secondary analyses evaluated cost effectiveness in adults aged $\geq 50$ years. The perspective of the publicly funded healthcare system was adopted.

\subsection{Input Parameters}

Similar to the models in Curran et al. [22, 25], VE and waning for both RZV and ZVL were modeled based on the respective Phase III clinical trials comparing each vaccine 
to placebo [21, 30-32] (Table 1 and SI). Other input parameters, including demographic parameters (SI Table 1), epidemiological parameters (SI Table 2), utilities (Table 2), and costs (Table 3 ) were derived from Canadian-specific literature. Detailed description of the modeling assumptions, including waning rates, and source data used to derive basecase input parameters and ranges for deterministic sensitivity analyses (DSAs) and probabilistic sensitivity analyses (PSA) are provided in SI.

Vaccine costs were set to Canadian list prices. The price per dose of RZV was set to $\$ 122$, with a range of $\$ 115.90-\$ 128.10$ used in one-way sensitivity analyses. The price per dose of ZVL was $\$ 176.77$, based on the private sector price per dose listed in the IMS Canada Price List and was not varied in sensitivity analyses. For the reference case, an administration cost of $\$ 4.50$ was obtained from the Ontario Ministry of Health and Long-Term Care schedule of benefits, assuming that the first dose would occur during a physician visit where immunization was not the primary goal [33]. It was assumed that the second dose of RZV would be administered during a general practitioner visit scheduled for this purpose, which would lead to an additional cost of $\$ 5.10$ according to the Ontario Schedule of Benefits.

For sources prior to 2016, costs were inflated to 2016 Canadian dollars using the Health and Personal Care component of the Consumer Price Index [34].

\subsection{Deterministic and Probabilistic Sensitivity Analyses}

DSAs were performed, during which parameters were changed one at a time according to their pre-defined ranges. Tornado diagrams were constructed to highlight parameters with the largest impact on Incremental costeffectiveness ratios (ICERs). PSAs were carried out using Monte Carlo simulations (5000 iterations) during which parameters were changed simultaneously in a random fashion within their pre-defined range. All parameters were varied according to a beta-distribution, except for costs and vaccine coverage rates, which followed gamma and uniform distributions, respectively.

\subsection{Outcomes}

Total number of HZ and PHN cases, complications and deaths were computed as well as QALYs and costs accrued throughout the remaining lifetime. The number needed to vaccinate, and life-years saved were estimated. ICERs for both comparisons (i) RZV versus no vaccination and (ii) RZV versus ZVL were calculated and compared against the commonly used willingness-to-pay (WTP) threshold of $\$ 50,000$ per QALY gained. In addition, WTP thresholds of $\$ 30,000$ and $\$ 100,000$ were used in threshold analyses.

\section{Results}

In the base-case analysis of people aged $\geq 60$ years, RZV would prevent 554,504 and 166,196 cases of HZ and PHN, respectively, compared with no vaccination (Table 4). The number needed to vaccinate to prevent one $\mathrm{HZ}$ case is 11 , and 34 to prevent one PHN case. RZV leads to a reduction in HZ-related complications, general practitioner visits,
Table 2 Utilities and utility decrements base input values, ranges and standard deviations used for sensitivity analyses

\begin{tabular}{|c|c|c|c|c|}
\hline Age group (years) & Base-case value & Range & Standard deviation & References \\
\hline \multicolumn{5}{|l|}{ Utility values, no $\mathrm{HZ}$} \\
\hline $50-59$ & 0.9200 & $0.9170,0.9229$ & 0.00152 & \multirow[t]{5}{*}{ Mittmann et al. [43] } \\
\hline $60-64$ & 0.9100 & $0.9064,0.9135$ & 0.00188 & \\
\hline $65-69$ & 0.9100 & $0.9064,0.9135$ & 0.00188 & \\
\hline $70-79$ & 0.9100 & $0.9050,0.9149$ & 0.00254 & \\
\hline$\geq 80$ & 0.8800 & $0.8722,0.8877$ & 0.00397 & \\
\hline \multicolumn{5}{|c|}{ QALY loss per HZ-only case ${ }^{\mathrm{a}}$} \\
\hline All age groups & 0.03600 & $0.0270,0.0450$ & 0.0045 & Drolet et al. [9] \\
\hline \multicolumn{5}{|c|}{ QALY loss per PHN-only case ${ }^{\mathrm{a}}$} \\
\hline All age groups & 0.13570 & $0.1017,0.1696$ & 0.0173 & Drolet et al. [9] \\
\hline \multicolumn{5}{|c|}{ QALY loss per AEs, all age groups ${ }^{\mathrm{a}}$} \\
\hline Local/general & 0.000100 & $0.00009,0.00011$ & - & \multirow[t]{2}{*}{ Le and Rothberg [44] } \\
\hline Serious (hospitalization) & 0.008200 & $0.00738,0.00902$ & - & \\
\hline
\end{tabular}

Utilities for $\mathrm{HZ}$ and PHN health states and costs associated with the management of $\mathrm{HZ}$ and PHN are assumed to be the same in vaccinated and unvaccinated subjects

$A E$ adverse event, $H Z$ herpes zoster, $P H N$ postherpetic neuralgia, $Q A L Y$ quality-adjusted life-year

${ }^{a}$ QALYs are corrected for length of illness. QALY loss is varied $+25 \%$ and $-25 \%$ in sensitivity analyses 
Table 3 Cost base input values, ranges, and standard deviations used for sensitivity analyses

\begin{tabular}{|c|c|c|c|c|}
\hline Age group (years) & Base value & Range & Standard deviation & References \\
\hline \multicolumn{5}{|l|}{ Cost per HZ case, $\$$} \\
\hline $50-59$ & 264 & $211.20,316.80$ & 26.94 & \multirow{5}{*}{$\begin{array}{l}\text { Friesen et al. [12]; Ontario } \\
\text { calculations }^{\mathrm{a}}\end{array}$} \\
\hline $60-64$ & 264 & $211.20,316.80$ & 26.94 & \\
\hline $65-69$ & 301 & $240.80,361.20$ & 30.71 & \\
\hline $70-79$ & 301 & $240.80,361.20$ & 30.71 & \\
\hline$\geq 80$ & 301 & $240.80,361.20$ & 30.71 & \\
\hline \multicolumn{5}{|c|}{ Cost per PHN case, $\$$} \\
\hline $50-59$ & 921 & $571.02,1270.98$ & 178.56 & \multirow{5}{*}{$\begin{array}{l}\text { Friesen et al. [12]; Ontario } \\
\text { calculations }^{\mathrm{a}}\end{array}$} \\
\hline $60-64$ & 921 & $571.02,1270.98$ & 178.56 & \\
\hline $65-69$ & 1639 & $571.02,1270.98$ & 317.77 & \\
\hline $70-79$ & 1639 & $571.02,1270.98$ & 317.77 & \\
\hline$\geq 80$ & 1639 & $1016.18,2261.82$ & 317.77 & \\
\hline \multicolumn{5}{|c|}{ Vaccine cost, RZV, \$ } \\
\hline All age groups & 122 & $115.90,128.10$ & - & IMS \\
\hline \multicolumn{5}{|c|}{ Vaccine cost, ZVL, \$ } \\
\hline All age groups & 176.77 & - & - & IMS \\
\hline \multicolumn{5}{|c|}{ Vaccine administration, $\$$} \\
\hline First dose & 4.50 & $4.50,9.60$ & & \multirow[t]{2}{*}{ Ontario calculations $^{\mathrm{a}}$} \\
\hline Second dose & 9.60 & $4.50,9.60$ & & \\
\hline \multicolumn{5}{|c|}{ Costs due to AEs per vaccinated individual, RZV, \$ } \\
\hline $50-59$ & 2.88 & $1.44,4.32$ & 0.734 & \multirow[t]{5}{*}{ Ontario calculations $^{\mathrm{a}}$} \\
\hline $60-64$ & 2.62 & $1.31,3.93$ & 0.668 & \\
\hline $65-69$ & 2.89 & $1.45,4.34$ & 0.737 & \\
\hline $70-79$ & 2.81 & $1.41,4.22$ & 0.716 & \\
\hline$\geq 80$ & 2.81 & $1.41,4.22$ & 0.716 & \\
\hline \multicolumn{5}{|c|}{ Costs due to AEs per vaccinated individual, ZVL, $\$$} \\
\hline $50-59$ & 1.70 & $0.85,2.55$ & 0.433 & \multirow[t]{5}{*}{ Ontario calculation $^{\mathrm{a}}$} \\
\hline $60-64$ & 1.70 & $0.85,2.55$ & 0.433 & \\
\hline $65-69$ & 1.70 & $0.85,2.55$ & 0.433 & \\
\hline $70-79$ & 1.70 & $0.85,2.55$ & 0.433 & \\
\hline$\geq 80$ & 1.70 & $0.85,2.55$ & 0.433 & \\
\hline
\end{tabular}

All \$ refer to Canadian dollars

$A E$ adverse event, $H Z$ herpes zoster, $P H N$ postherpetic neuralgia, $R Z V$ adjuvanted recombinant zoster vaccine, $Z V L$ zoster vaccine live ${ }^{a}$ Derived from Ontario Ministry of Health and Long-term Care (MOHLTC) fee schedules and Ontario Case Costing Initiative (OCCI)

and hospitalizations and an increase in QALYs gained. Cost associated with vaccination is partially offset by savings in direct costs due to the management of $\mathrm{HZ}$ and PHN; however, vaccination leads to a net increase in direct costs, resulting in an ICER of \$28,360/QALY for RZV versus no vaccination (Table 5).

Compared with ZVL, RZV would prevent an additional 391,293 cases of HZ and 96,968 cases of PHN, while increasing direct costs. The ICER of RZV versus ZVL is \$2396/QALY (Table 5).

One-way DSA showed that the ICERs for RZV versus no vaccination in adults aged $\geq 60$ years were most sensitive to changes in annual waning rates of two-dose $\mathrm{VE}_{\mathrm{HZ}}$ of RZV in the age group $\geq 70$ years, annual incidence of
HZ, percentage of initial HZ cases with PHN (Fig. 2). The highest ICER was observed when the annual incidence of initial HZ was at its lower bound $(\$ 38,356)$. The ICERs remained well below the WTP threshold of $\$ 50,000 /$ QALY, which is a threshold often used in cost-effectiveness studies in Canada (Fig. 2). In the PSA comparing RZV with no vaccination, $99.2 \%$ of simulations resulted in an ICER below the WTP threshold of $\$ 50,000$ per QALY gained (Fig. 3). There were $63.5 \%$ of simulations below a threshold of \$30,000 per QALY gained while all simulations remained below a threshold of $\$ 100,000$ per QALY gained.

The one-way DSA for the comparison of RZV versus ZVL showed that the ICERs were sensitive to changes in 
Table $4 \mathrm{HZ}$ and PHN cases for base-case scenario in adults aged $\geq 60$ years

\begin{tabular}{llllll}
\hline Outcomes & RZV & No vaccination & ZVL & $\begin{array}{l}\text { \# Cases avoided (RZV } \\
\text { vs no vaccination) }\end{array}$ & $\begin{array}{l}\text { \# Cases } \\
\text { avoided (RZV } \\
\text { vs ZVL) }\end{array}$ \\
\hline HZ cases & 727,067 & $1,281,571$ & $1,118,360$ & 554,504 & 391,293 \\
PHN cases & 236,033 & 402,228 & 333,001 & 166,196 & 96,968 \\
Complication cases & 104,010 & 177,721 & 158,326 & 73,711 & 54,316 \\
Ocular & 34,888 & 59,142 & 52,591 & 24,253 & 17,703 \\
Neurological & 34,532 & 60,741 & 53,655 & 26,209 & 19,122 \\
Cutaneous & 15,820 & 26,247 & 23,761 & 10,427 & 7941 \\
Other non-pain & 18,770 & 31,591 & 28,319 & 12,821 & 9549 \\
HZ-related deaths & 427 & 640 & 614 & 212 & 186 \\
\hline
\end{tabular}

$H Z$ herpes zoster, $P H N$ postherpetic neuralgia, $R Z V$ adjuvanted recombinant zoster vaccine, ZVL zoster vaccine live

Table 5 Incremental cost-effectiveness ratios for base-case scenario in adults aged $\geq 60$ years

\begin{tabular}{|c|c|c|c|c|c|}
\hline Outcomes & RZV & No vaccination & ZVL & $\begin{array}{l}\text { Difference }^{\mathrm{a}}(\mathrm{RZV} \\
\text { vs no vaccination) }\end{array}$ & $\begin{array}{l}\text { Difference }^{\mathrm{a}} \\
\text { (RZV vs } \\
\text { ZVL) }\end{array}$ \\
\hline \multicolumn{6}{|l|}{ Life-years/QALYs (discounted at 1.5\%) } \\
\hline Life-years & $107,495,705$ & $107,494,014$ & $107,494,305$ & 1691 & 1401 \\
\hline QALYs & $96,578,202$ & $96,544,742$ & $96,556,869$ & 33,460 & 21,334 \\
\hline \multicolumn{6}{|c|}{ Costs associated with vaccine program, $(\$$, discounted at $1.5 \%)$} \\
\hline Vaccination costs & $1,286,463,213$ & 0 & $1,024,290,348$ & $1,286,463,213$ & $262,172,865$ \\
\hline Direct costs due to $\mathrm{HZ}$ and complications & $427,855,341$ & $765,404,926$ & $638,908,525$ & $-337,549,585$ & $-211,053,184$ \\
\hline Total direct costs & $1,714,318,554$ & $765,404,926$ & $1,663,198,873$ & $948,913,628$ & $51,119,681$ \\
\hline \multicolumn{6}{|c|}{ Cost-effectiveness, \$ per QALY gained (discount rates in parenthesis) } \\
\hline Base-case: incremental cost per QALY (1.5\%) & & & & 28,360 & 2396 \\
\hline Incremental cost per QALY $(0 \%)$ & & & & 24,139 & 801 \\
\hline Incremental cost per QALY (3\%) & & & & 32,688 & 4100 \\
\hline Incremental cost per QALY (5\%) & & & & 38,577 & 6516 \\
\hline
\end{tabular}

All \$ represent Canadian dollars

$H Z$ herpes zoster, $P H N$ postherpetic neuralgia, $Q A L Y$ quality-adjusted life-year, $R Z V$ adjuvanted recombinant zoster vaccine, $Z V L$ zoster vaccine live

${ }^{\text {a }}$ Values in table are rounded so differences do not always sum

second-dose compliance with RZV, annual waning rates of two-dose $V E_{\mathrm{HZ}}$ of RZV in the age group aged $\geq 70$ years, and RZV vaccine price per dose (Fig. 4).

In the PSA comparing RZV with ZVL, approximately half of the simulations (48.2\%) were cost-neutral or resulted in cost savings, and $100 \%$ of the simulations resulted in an ICER below the WTP threshold of $\$ 50,000$ per QALY gained (SI Fig. 1).

Compared with no vaccination, the number of $\mathrm{HZ}$ and PHN cases avoided was almost doubled when considering people aged $\geq 50$ years for vaccination, mainly because of the larger population in this cohort (SI Tables 1 and 5). The number needed to vaccinate was 10 to prevent one case of $\mathrm{HZ}$ and 37 to prevent one case of PHN. The ICER of $\$ 30,402$ is similar to the base-case scenario (SI Table 6). The ICER of RZV versus ZVL for this population equates to $\$ 2513$ (SI Table 6). One-way DSA carried out for the secondary analyses were consistent with findings from the primary analyses: discount rates for health outcomes, $\mathrm{VE}_{\mathrm{HZ}}$ waning rates, annual incidence of $\mathrm{HZ}$ and percentage of initial HZ cases with PHN had the largest impact on ICERs of RZV versus the no-vaccination strategy (SI Figs. 2-4). Furthermore, RZV was cost-saving compared with ZVL in $47.4 \%$ of PSA simulations (SI Fig. 5).

\section{Discussion}

In Canadian adults aged $\geq 60$ years, RZV was predicted to be cost effective compared with no vaccination and compared with vaccination with ZVL. The corresponding ICERs were $\$ 28,360$ and $\$ 2396$ for RZV versus no 


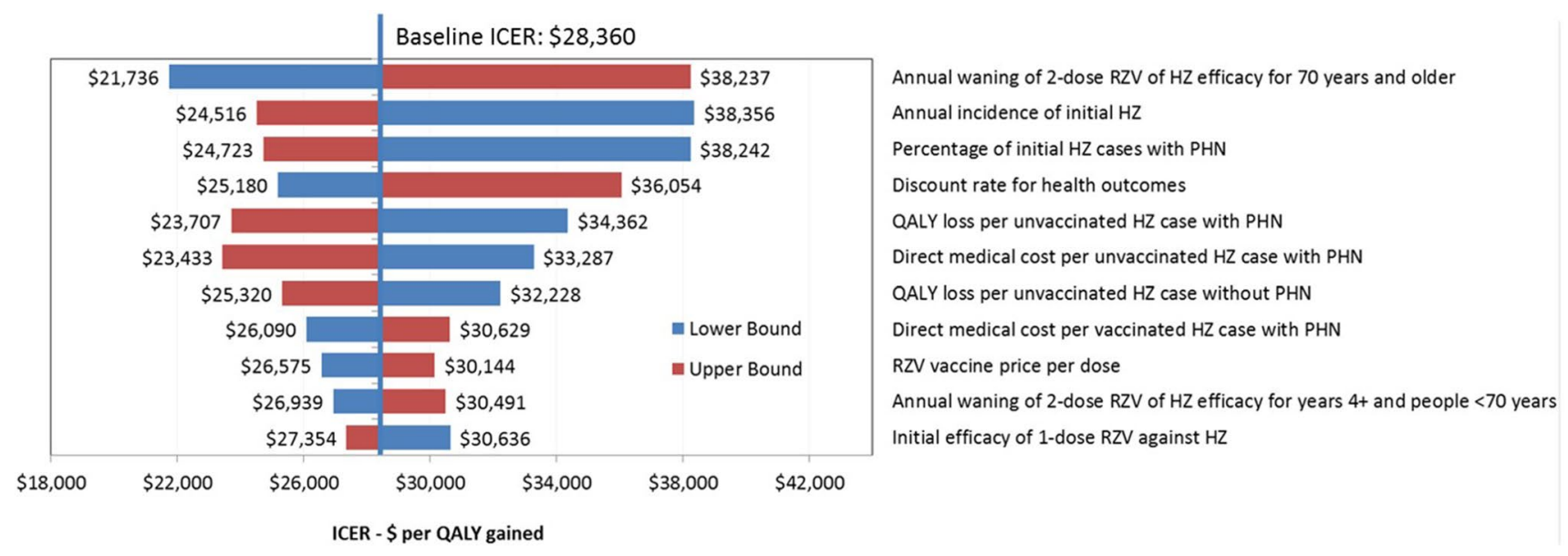

Fig. 2 One-way sensitivity analysis results for ICER of RZV versus no vaccination for adults aged $\geq 60$ years. The Tornado diagram is truncated at the first 11 variables with the highest impact on ICER.
$H Z$ herpes zoster, ICER incremental cost-effectiveness ratio, $P H N$ postherpetic neuralgia, $Q A L Y$ quality-adjusted life-year, $R Z V$ adjuvanted recombinant zoster vaccine, $Z V L$ zoster vaccine live
Fig. 3 Cost-effectiveness acceptability curve from probabilistic sensitivity analyses for adults aged $\geq 60$ years (A) RZV versus no vaccination; (B): RZV versus ZVL. ICER incremental cost-effectiveness ratio, $Q A L Y$ quality-adjusted life-year, $R Z V$ adjuvanted herpes zoster subunit vaccine, $W T P$ willingness to pay, $Z V L$ zoster vaccine life

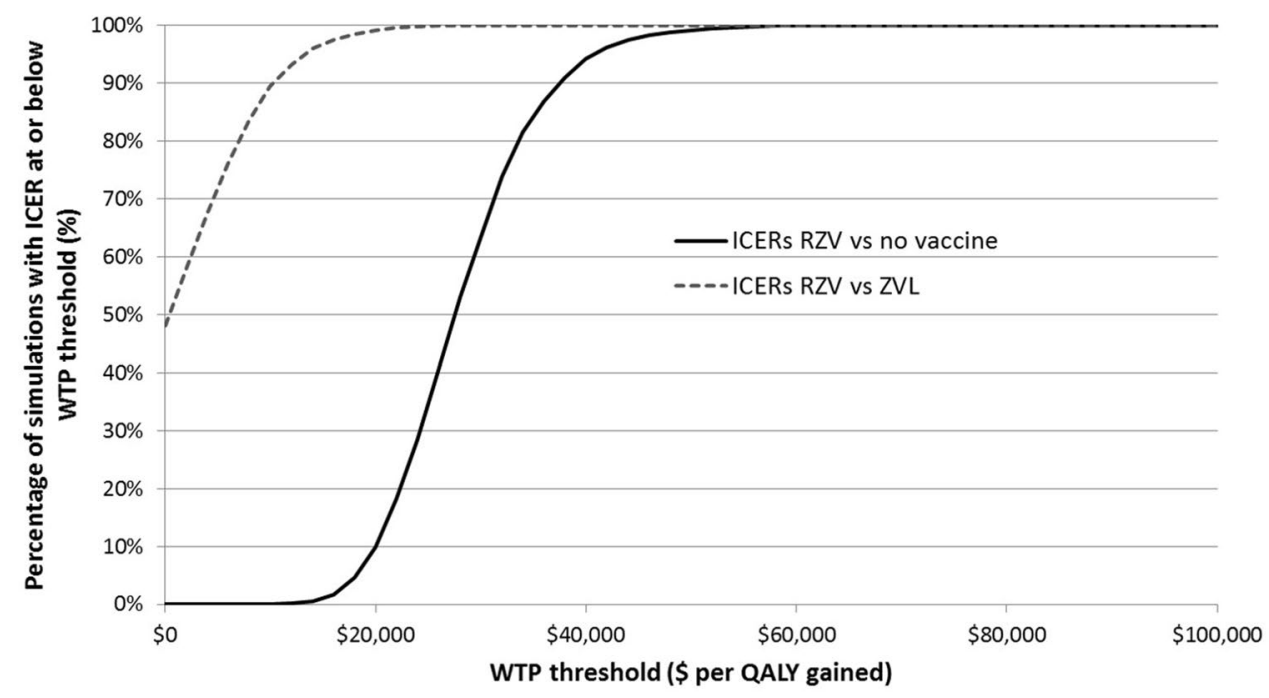

To account for uncertainties around second-dose compliance in the real-world setting, this parameter was varied through a wide range in sensitivity analyses. Counterintuitively, DSAs showed that lower compliance leads to a more favorable ICER. This can be explained by two factors: (i) One-dose RZV is less expensive than ZVL but has comparable efficacy, and (ii) the effect of discounting; two RZV doses are paid in advance but positive outcomes are only seen several years later. It should be noted that RZV was developed as a two-dose vaccine based on Phase I and Phase II clinical data showing that cellular immune response was three times higher after two doses of RZV compared to one [35]. This in turn leads to a substantial improvement in public health impact when increasing second-dose compliance [36]. 


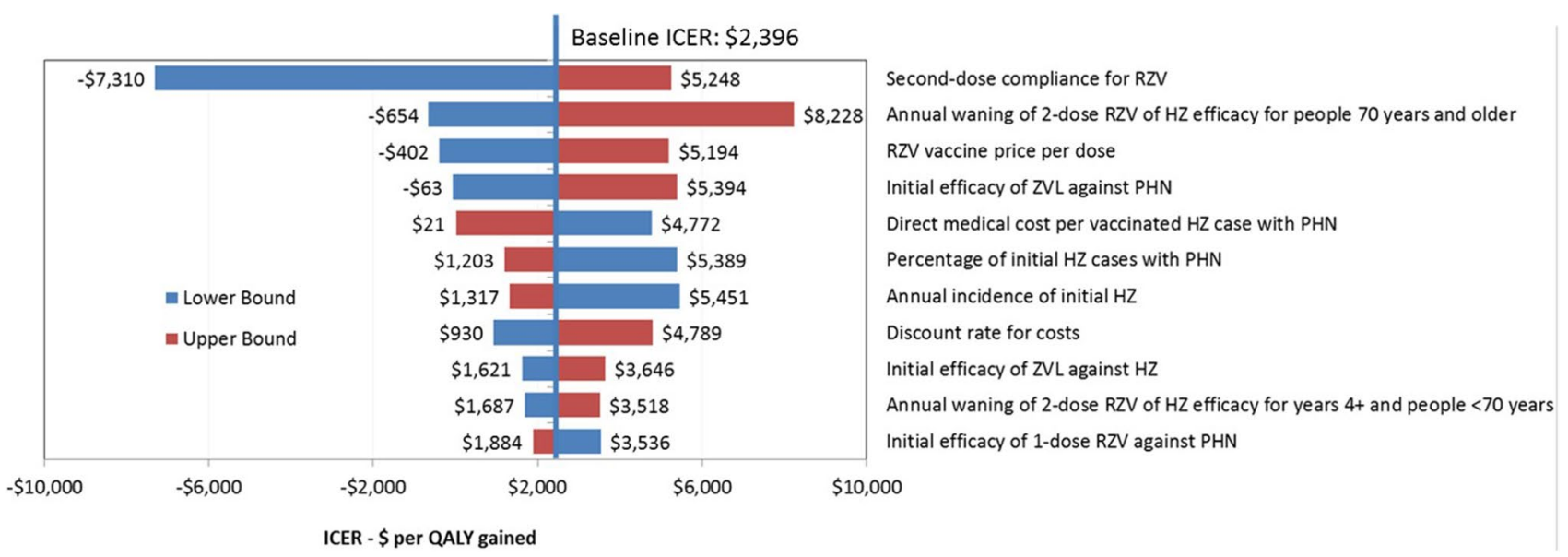

Fig. 4 One-way sensitivity analysis results for ICER of RZV versus ZVL for adults aged $\geq 60$ years. $H Z$ herpes zoster, ICER incremental cost-effectiveness ratio, $P H N$ postherpetic neuralgia, $Q A L Y$ quality-

In developing recommendations for the use of RZV and ZVL in Canada, both the National Advisory Committee on Immunization and the Comité sur l'immunisation du Québec published results from cost-effectiveness analyses of both vaccines [23, 24]. Both studies demonstrated that RZV and ZVL would be considered cost effective against commonly used thresholds but indicated the RZV was more cost effective than ZVL at similar price points.

Additionally, we identified two cost-effectiveness studies comparing ZVL with a no-vaccination strategy for different age groups conducted in the Canadian setting [37, 38]. Both studies suggested that with a WTP threshold of $\$ 50,000 /$ QALY, ZVL would be cost effective in individuals aged 60 or $\geq 65$ years, respectively, though most recent ZVL waning data were not yet included in these models. In a model developed by the US Centers for Disease Control and Prevention (CDC) that uses updated long-term ZVL efficacy data, the ICER for ZVL increased to more than $\$$ US 80,000/ QALY gained for adults aged $\geq 60$ years, due to the more pronounced waning rate of ZVL [39]. Two recent adaptations of the model used in this analysis have been published demonstrating the German and US cost-effectiveness results $[25,40]$. While the results are generally aligned to those presented here, the differences between the countries, the vaccine uptake rates, healthcare utilization rates, and costs associated with medical care contributed to the different ICER results. The US adaptation was also updated to examine the potential cost effectiveness of revaccinating adults who had previously been immunized with ZVL. The results demonstrated that vaccination with RZV is cost effective compared to no vaccination at $\$ 100,000 \mathrm{WTP}$ in those previously immunized with ZVL [41]. Finally, two independent models including RZV and ZVL have recently been developed for the US context. One model by the CDC served as adjusted life-year, $R Z V$ adjuvanted recombinant zoster vaccine, $Z V L$ zoster vaccine live

a basis for the preferential recommendation of RZV over ZVL issued by the Advisory Committee on Immunization Practice. A second model developed by Le and Rothberg suggested that RZV was highly cost effective against no vaccination and cost saving compared with ZVL at a WTP threshold of \$US 50,000/QALY, even under the conservative assumptions regarding second-dose RZV compliance (set to $56.2 \%$ ) and a RZV waning rate equal to that observed for $\mathrm{ZVL}$ and doubled in case of one-dose RZV [42].

The main limitations of this study are that no real-world data for RZV effectiveness and no RZV VE persistence data beyond year 4 after vaccination are available. The impact of waning rates has been explored by one-way sensitivity analyses showing that ICERs were sensitive to the waning rate, although RZV remains cost effective even at the estimated upper bound for waning rate of $6.6 \%$. Assumptions had to be made for coverage and second-dose compliance due to lack of real-world data. To account for uncertainties in these variables, a wide range of values were used in sensitivity analyses revealing no significant impact on ICERs. The cost-utility analysis needs to be reevaluated once additional data become available, such as real-world coverage and compliance rates.

The model assumed that utilities of the HZ and PHN health state were the same regardless of vaccination strategy. This assumption ignores a possible impact of vaccination on the severity of HZ and PHN and would thereby underestimate incremental QALY gain with vaccination strategies. It would be important to investigate the impact of vaccination on duration and severity of $\mathrm{HZ}$ and PHN episodes in break-through cases; data from the ZOE-50 and ZOE-70 trials suggest that duration and severity of pain in vaccinated individuals are lower as compared to unvaccinated individuals [36]. Finally, list prices for RZV and ZVL were used; if 
RZV was to be included in public health plans, lower contractual or tender prices could apply, leading to substantially lower ICERs.

In conclusion, RZV is a cost-effective option at the WTP threshold of \$50,000/QALY, for vaccinating Canadian adults aged $\geq 60$ years against $\mathrm{HZ}$ compared to no vaccination (ICER: \$28,360/QALY). Comparative analyses with ZVL suggested that RZV would be cost-effective versus ZVL (ICER: \$2396/QALY) when vaccinating Canadian adults aged $\geq 60$ years. Results for the Canadian population aged $\geq 50$ years were similar. These results were robust to a variety of sensitivity analyses and variation in key parameters. Findings were consistent with other cost-effectiveness models, which conclude that RZV would be cost effective versus no vaccination and ZVL under most circumstances tested.

Acknowledgements Authors would like to thank Shireen Khaliq and Amyn Sayani (both GSK Canada) and Mohamed Neine and Stephane Lorenc (Freelance consultants on behalf of GSK) for their help in the conduct of this analysis. They also thank Business \& Decision Life Sciences platform for editorial assistance and publications coordination, on behalf of GSK. Stephanie Garcia coordinated manuscript development and editorial support. Katrin Spiegel provided writing support.

\section{Compliance with Ethical Standards}

Funding GlaxoSmithKline Biologicals SA funded this study (GSK study identifier: HO-15-15891) and was involved in all stages of study conduct, including analysis of the data. GlaxoSmithKline Biologicals SA also covered all costs associated with the development and publication of this manuscript.

Conflict of interest AMG, DVO, RW, LV and DC are employees of the GSK group of companies and DC holds shares in the GSK group of companies. MS and MG are employees of Evidera, a consulting firm that received fees from the GSK group of companies to conduct of these analyses. During the conduct of this study, HJ was also an employee of Evidera.

Trademark Shingrix is a trademark of the GSK group of companies. Zostavax is a trademark from Merck Sharp \& Dohme Corp.

Author contributions AM, DVO, RW, MS and DC participated to the conception of the analysis and adaptation of the model. All authors were involved in the data collection. AM, DVO, MS, HJ and DC performed the analysis. AM, DVO, RW, MS, HJ, LV and DC participated to the interpretation of the data. All authors had full access to the data, reviewed the manuscript and approved the final version of the paper for submission.

Data sharing GSK makes available anonymized individual participant data and associated documents from interventional clinical studies which evaluate medicines, upon approval of proposals submitted to http://www.clinicalstudydatarequest.com. To access data for other types of GSK sponsored research, for study documents without patientlevel data and for clinical studies not listed, please submit an enquiry via the website.

Open Access This article is distributed under the terms of the Creative Commons Attribution-NonCommercial 4.0 International License (http://creativecommons.org/licenses/by-nc/4.0/), which permits any noncommercial use, distribution, and reproduction in any medium, provided you give appropriate credit to the original author(s) and the source, provide a link to the Creative Commons license, and indicate if changes were made.

\section{References}

1. Brisson M, Edmunds WJ, Gay NJ, Law B, De Serres G. Modelling the impact of immunization on the epidemiology of varicella zoster virus. Epidemiol Infect. 2000;125(3):651-69. https://doi. org/10.1017/S0950268800004714.

2. Brisson M, Edmunds WJ, Law B, Gay NJ, Walld R, et al. Epidemiology of varicella zoster virus infection in Canada and the United Kingdom. Epidemiol Infect. 2001;127:305-14. https://doi. org/10.1017/S0950268801005921.

3. Yawn BP, Gilden D. The global epidemiology of herpes zoster. Neurology. 2013;81(10):928-30. https://doi.org/10.1212/ WNL.0b013e3182a3516e.

4. Kawai K, Gebremeskel BG, Acosta CJ. Systematic review of incidence and complications of herpes zoster: towards a global perspective. BMJ Open. 2014;4:e004833. https://doi.org/10.1136/ bmjopen-2014-004833.

5. Schmidt-Ott R, Schutter U, Simon J, Nautrup BP, von Krempelhuber A, Gopala K, et al. Incidence and costs of herpes zoster and postherpetic neuralgia in German adults aged $\geq 50$ years: a prospective study. J Infect. 2018;76(5):475-82. https://doi. org/10.1016/j.jinf.2018.02.001.

6. Drolet M, Brisson M, Schmader K, Levin M, Johnson R, Oxman $\mathrm{M}$, et al. Predictors of postherpetic neuralgia among patients with herpes zoster: a prospective study. J Pain. 2010;11(11):1211-21. https://doi.org/10.1016/j.jpain.2010.02.020.

7. Yawn BP, Saddier P, Wollan PC, St Sauver JL, Kurland MJ, Sy LS. A population-based study of the incidence and complication rates of herpes zoster before zoster vaccine introduction. Mayo Clin Proc. 2007;82(11):1341-9.

8. Johnson RW, Alvarez-Pasquin M-J, Bijl M, Franco E, Gaillat J, Clara JG, et al. Herpes zoster epidemiology, management, and disease and economic burden in Europe: a multidisciplinary perspective. Ther Adv Vaccines. 2015;3(4):109-20. https://doi. org/10.1177/2051013615599151.

9. Drolet M, Brisson M, Schmader KE, Levin MJ, Johnson R, Oxman MN, et al. The impact of herpes zoster and postherpetic neuralgia on health-related quality of life: a prospective study. CMAJ. 2010;182(16):1731-6. https://doi.org/10.1503/cmaj.09171 1.

10. Canadian Pain Society Study Day Participants. Safety and effectiveness of the herpes zoster vaccine to prevent postherpetic neuralgia : 2014 update and consensus statement from the Canadian Pain society. Pain Res Manag. 2015;20(1):46-7.

11. Marra F, Chong M, Najafzadeh M. Increasing incidence associated with herpes zoster infection in British Columbia, Canada. BMC Infect Dis. 2016;16(1):589. https://doi.org/10.1186/s1287 9-016-1898-z.

12. Friesen KJ, Chateau D, Falk J, Alessi-Severini S, Bugden S. Cost of shingles: population based burden of disease analysis of herpes zoster and postherpetic neuralgia. BMC Infect Dis. 2017;17(1):69. https://doi.org/10.1186/s12879-017-2185-3.

13. Gater A, Abetz-Webb L, Carroll S, Mannan A, Serpell M, Johnson R. Burden of herpes zoster in the UK: findings from the zoster quality of life (ZQOL) study. BMC Infect Dis. 2014;14(1):402. https://doi.org/10.1186/1471-2334-14-402. 
14. Sacks GM. Unmet need in the treatment of postherpetic neuralgia. Am J Manag Care. 2013;19(1 Suppl):S207-13.

15. Varghese L, Standaert B, Olivieri A, Curran D. The temporal impact of aging on the burden of herpes zoster. BMC Geriatr. 2017;17(1):30. https://doi.org/10.1186/s12877-017-0420-9.

16. National Advisory Committee on Immunization. An Advisory Committee Statement (ACS): update on the use of herpes zoster vaccine. 2014. https://www.canada.ca/content/dam/phac-aspc/ documents/services/publications/healthy-living/update-use-herpe s-zoster-vaccine/hzv-vcz-eng.pdf. Accessed 13 June 2018.

17. Merck Canada Inc. Product monograph: Zostavax. 2017. https:// pdf.hres.ca/dpd_pm/00042265.PDF. Accessed 13 June 2018.

18. Morrison VA, For the Shingles Prevention Study Group, Johnson GR, For the Shingles Prevention Study Group, Schmader KE, For the Shingles Prevention Study Group, et al. Long-term persistence of zoster vaccine efficacy. Clin Infect Dis. 2015;60(6):900-9. https ://doi.org/10.1093/cid/ciu918.

19. GlaxoSmithKline Inc. Product monograph: Shingrix. 2017. https ://ca.gsk.com/media/1350788/shingrix_pm-2017-10-13.pdf. Accessed 13 June 2018

20. Chlibek R, Pauksens K, Rombo L, van Rijckevorsel G, Richardus JH, Plassmann G, et al. Long-term immunogenicity and safety of an investigational herpes zoster subunit vaccine in older adults. Vaccine. 2016;34(6):863-8. https://doi.org/10.1016/j.vacci ne.2015.09.073.

21. Cunningham AL, Lal H, Kovac M, Chlibek R, Hwang S-J, DíezDomingo J, et al. Efficacy of the herpes zoster subunit vaccine in adults 70 years of age or older. N Engl J Med. 2016;375(11):1019_ 32. https://doi.org/10.1056/NEJMoa1603800.

22. Curran D, Van Oorschot D, Varghese L, Oostvogels L, Mrkvan $\mathrm{T}$, Colindres R, et al. Assessment of the potential public health impact of Herpes Zoster vaccination in Germany. Hum Vaccines Immunother. 2017;13(10):2213-21. https://doi.org/10.1080/21645 515.2017.1345399.

23. National Advisory Committee on Immunization (NACI). An Advisory Committee Statement (ACS): updated recommendations on the use of herpes zoster vaccines. 2018. https://www.canada.ca/ content/dam/phac-aspc/documents/services/publications/healthyliving/updated-recommendations-use-herpes-zoster-vaccines-eng. pdf. Accessed 05 Mar 2019.

24. Comité sur l'immunisation du Québec. Avis sur la pertinence d'ajouter la vaccination contre le zona au Programme québécois d'immunisation. 2018. https://www.inspq.qc.ca/publicatio ns/2381. Accessed 22 June 2018.

25. Curran D, Patterson B, Varghese L, Van Oorschot D, Buck P, Carrico J, et al. Cost-effectiveness of an adjuvanted recombinant zoster vaccine in older adults in the United States. Vaccine. 2018;36(33):5037-45. https://doi.org/10.1016/j.vacci ne.2018.07.005.

26. Oxman MN, Levin MJ, Johnson GR, Schmader KE, Straus SE, Gelb LD, et al. A vaccine to prevent herpes zoster and postherpetic neuralgia in older adults. N Engl J Med. 2012;366(20):185969. https://doi.org/10.1056/NEJMoa1208410.

27. Public Health Agency of Canada. Influenza vaccine uptake: results from the 2015/16 national influenza immunization coverage survey in Canada. 2016. https://www.canada.ca/en/public-healt $\mathrm{h} /$ services/publications/healthy-living/vaccine-uptake-results2015-16-national-influenza-immunization-coverage-survey.html. Accessed 13 June 2018.

28. Nelson JC, Bittner RCL, Bounds L, Zhao S, Baggs J, Donahue JG, et al. Compliance with multiple-dose vaccine schedules among older children, adolescents, and adults: Results from a vaccine safety datalink study. Am J Public Health. 2009;99(SUPPL. 2):389-97. https://doi.org/10.2105/AJPH.2008.151332.

29. CADTH. Guidelines for the economic evaluation of health technologies: Canada, 4th ed. 2017. https://www.cadth.ca/guidelines -economic-evaluation-health-technologies-canada-4th-edition. Accessed 13 June 2018.

30. Lal H, Cunningham AL, Godeaux O, Chlibek R, Diez-Domingo J, Hwang S-J, et al. Efficacy of an adjuvanted herpes zoster subunit vaccine in older adults. N Engl J Med. 2015;372(22):2087-96. https://doi.org/10.1056/NEJMoa1501184.

31. Schmader KE, Levin MJ, Gnann JW, McNeil SA, Vesikari T, Betts RF, et al. Efficacy, safety, and tolerability of herpes zoster vaccine in persons aged 50-59 years. Clin Infect Dis. 2012;54(7):922-8. https://doi.org/10.1093/cid/cir970.

32. Oxman MN, Levin MJ, Johnson GR, Schmader KE, Straus SE, Gelb LD, et al. A vaccine to prevent herpes zoster and postherpetic neuralgia in older adults. N Engl J Med. 2005;352(22):227184. https://doi.org/10.1056/NEJMoa051016.

33. Ontario Ministry of Health Long-Term Care. Schedule of benefits physician services under the health insurance act (December 22, 2015 (effective March 1, 2016)) 2016. http://www.health.gov. on.ca/en/pro/programs/ohip/sob/. Accessed 1 Oct 2017.

34. Statistics Canada. Consumer Price Index, by province (monthly). 2017. http://www.statcan.gc.ca/tables-tableaux/sum-som/101/ cst01/cpis01a-eng.htm. Accessed 13 June 2018.

35. Chlibek R, Smetana J, Pauksens K, Rombo L, Van den Hoek JAR, Richardus JH, et al. Safety and immunogenicity of three different formulations of an adjuvanted varicella-zoster virus subunit candidate vaccine in older adults: a phase II, randomized, controlled study. Vaccine. 2014;32(15):1745-53. https://doi.org/10.1016/j. vaccine.2014.01.019.

36. Curran D, Athan E, Diez-Domingo J, Ghesquiere W, Heineman TC, Lal H, et al. Quality-of-life impact of an investigational subunit-adjuvanted herpes zoster vaccine in adults $\geq 50$ years of age. Open Forum Infect Dis. 2016. https://doi.org/10.1093/ofid/ofw19 4.77.

37. Brisson M. Estimating the number needed to vaccinate to prevent herpes zoster-related disease, healthcare resource use and mortality. Can J Public Health. 2008;99:383-6.

38. Najafzadeh M, Marra CA, Galanis E, Patrick DM. Cost effectiveness of herpes zoster vaccine in Canada. Pharmacoeconomics. 2009;27(12):991-1004. https://doi.org/10.2165/11314010-00000 $0000-00000$

39. Hales CM, Harpaz R, Ortega-Sanchez I, Bialek SR. Update on recommendations for use of herpes zoster vaccine. MMWR Morb Mortal Wkly Rep. 2014;63(33):729-31.

40. Van Oorschot D, Anastassopoulou A, Poulsen Nautrup B, Varghese L, von Krempelhuber A, Neine M, et al. Cost-effectiveness of the recombinant zoster vaccine in the German population aged $\geq 60$ years old. Hum Vaccines Immunother. 2019;15(1):34-44. https://doi.org/10.1080/21645515.2018.1509645.

41. Curran D, Patterson BJ, Van Oorschot D, Buck PO, Carrico J, Hicks KA, et al. Cost-effectiveness of an adjuvanted recombinant zoster vaccine in older adults in the United States who have been previously vaccinated with zoster vaccine live. Hum Vaccines Immunother. 2019;15(4):765-71. https://doi.org/10.1080/21645 515.2018.1558689.

42. Le P, Rothberg MB. Cost-effectiveness of the adjuvanted herpes zoster subunit vaccine in older adults. JAMA Intern Med. 2018;178(2):248-58. https://doi.org/10.1001/jamaintern med.2017.7431.

43. Mittmann N, Trakas K, Risebrough N, Liu BA. Utility scores for chronic conditions in a community-dwelling population. PharmacoEconomics. 1999;15(4):369-76.

44. Le P, Rothberg MB. Cost-effectiveness of herpes zoster vaccine for persons aged 50 years. Ann Intern Med. 2015;163(7):489. https://doi.org/10.7326/m15-0093. 